\title{
Density of Dermatophagoides spp. and Its Relationship with House-dust Mite Specific Serum IgE in Persistent Asthma
}

\author{
Annisa Mulia Anasis ${ }^{1}$, Anna Rozaliyani², Heri Wibowo² \\ ${ }^{1}$ Master Program in Biomedical Science, Faculty of Medicine, Universitas Indonesia, Jakarta, Indonesia \\ ${ }^{2}$ Department of Parasitology, Faculty of Medicine, Universitas Indonesia, Jakarta, Indonesia
}

Background: Asthma is a chronic inflammation of the bronchial tree that emerges as a response to exogenous factors, such as allergens, irritants, and infections. Some asthmatic patients had been reported having symptoms of asthma due to house-dust mites (HDM) allergen exposure. It is associated with immune responses which were increased in the form of specific Immunoglobulin E (IgE) production against HDM allergens. This case-control study aimed to determine the HDM profiles in persistent asthmatic patients, including density of mites, as well as its relationship with specific IgE anti-HDM serum levels.

Materials and Methods: A total of 13 patients with persistent asthma and 12 control patients had their specific anti-HDM IgE levels examined using Immulite 2000 xpi. The house dust samples were taken and analyzed with the Fain method.

Results: The results have shown that $69 \%$ of patients in the persistent asthma group and $25 \%$ of normal patients were positive for IgE anti-HDM. Dermatophagoides pteronyssinus is a predominant species with a total of 120 mites (83.9\%) of 143 mites. Correlation analysis indicated a positive relationship between IgE anti-HDM levels within the serums of patients and the density of mites in the dust obtained from bedroom spaces (Spearmen Rho, $\mathrm{R}=0.35, p=0.04$ ).

Conclusion: Positive IgE anti-HDM patients in the persistent asthma group were higher (69\%) than those in the clinically normal group (25\%). The density of mites were dominated by $D$. Pteronyssinus. The bedroom-dust mites density revealed a positive correlation with serum IgE anti-HDM levels in persistent asthma patients.

Keywords: asthma, density, Dermatophagoides spp.,IgE

\section{Introduction}

Asthma is a chronic inflammatory disorder of the respiratory tract that occurs because of the body's response to various exogenous factors, including allergens, irritants, and viral infections. Exogenous factors that cause asthma include allergens derived from cockroaches, mites, cats, pollens and fungi. ${ }^{1,2}$ In 2007, data of asthma prevalences in Jakarta are about $7.5 \%$. The prevalent asthma in the world has increased in recent decades. It is estimated to rise up to 400 million people by 2025 . Approximately $50-80 \%$ cases of asthma in the world are triggered by house dust. Meanwhile, $90 \%$ of asthma patients in Indonesia are susceptible to house-dust exposure and house-dust mites (HDM) ${ }^{3-6}$

Date of submission: May 26, 2019

Last Revised: July 17, 2019

Accepted for publication: July 18, 2019

Corresponding Author:

Annisa Mulia Anasis

Master Program in Biomedical Science

Faculty of Medicine, Universitas Indonesia

Jl. Salemba Raya No.5, Jakarta, Indonesia

e-mail: annisa.syaddad@gmail.com

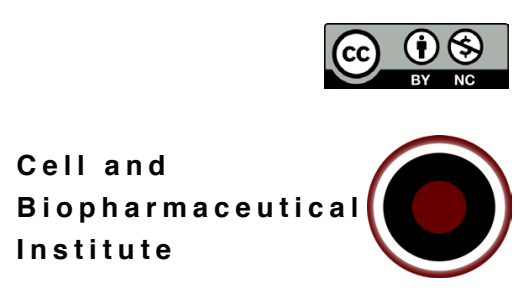


HDM are a source of allergens, for instance the rhinoconjunctivitis allergy, asthma, atopic dermatitis, and other skin diseases. ${ }^{7}$ Genetic and environmental interactions lead to inflammation of the chronic airways for asthma patients. This interactions can ensue due to various environmental factors, the most important of which are mite allergens and air pollution. ${ }^{8}$ Asthma patients experience developments of asthma symptoms by reason of house-dust exposure. This is associated with an increase of immune responses in the form of specific Immunoglobulin E (IgE) production of HDM allergens. ${ }^{9}$

The main source of HDM allergens comes from Dermatophagoides pteronyssinus, Dermatophagoides farinae and Euroglyphus maynei. Many ecological studies show that dust-mite species commonly discovered in the world are D. pteronyssinus and D. farinae. ${ }^{7,10}$ A number of allergic asthma patients indicate hypersensitive reactions to indoor allergens, including HDM. The role of environment in the room becomes a major concern to control asthma, considering that most of our lives are in indoors. Efforts to identify these environmental factors are very important, by knowing the type of HDM and the environment of living, the density of mites and their relationship with sensitization of HDM-specific IgE. Exposure to HDM as a cause of allergic asthma must be controlled as an important step to minimize clinical symptoms and prevent an asthma development. ${ }^{11,12}$

Data of HDM exposure, particularly Dermatophagoides spp., and its relationship with the levels of IgE anti-HDM and asthma symptoms in Indonesia are still limited whereas those data are extremely needed in order to prevent asthma, especially controlling its trigger factors. This research aimed to discover patient HDM profiles of persistent asthma patients, including HDM density, and its relationship with levels of anti-HDM IgE serums.

\section{Materials and methods}

\section{Population and Sample}

This was a case-controlled study among two groups, which were persistent asthma group and control group. The control group consisted of normal patients who have no medical records of asthma and allergies. Meanwhile the persistent asthma group consisted of asthma patients, which was obtained by purposive sampling from 2 different hospitals, Persahabatan and Graha Permata Ibu Hospitals, Jakarta.
Inclusion criteria were patients with the age $\geq 18$ years, settling at home for more than 1 year, and had a history of persistent asthma (for persistent asthma group), or had no history of asthma and atopy (for control group). The severity level of asthma was determined based on the Global Initiative on Asthma (GINA) 2015 criteria. Persistent asthma was defined as an asthma with symptoms occurred $>2$ days per week. The determination of age $\geq 18$ years was based on Asthma Clinical Research Network (ACRN) criteria. The ethical clearance was received from Faculty of Medicine, Universitas Indonesia (No. 420/UN2.F1/ETIK/2017).

\section{Blood Samples Collection}

About $3 \mathrm{cc}$ of blood samples were collected using serum saparator tube (SST) and left for 30-45 minutes until the blood was frozen. After freezed, the blood was spinned by a centrifuge at speed of 1300-2000 g for 15 minutes, then the serum (supernatant) was separated and inserted into the eppendorf tubes and stored at $-80^{\circ} \mathrm{C}$.

\section{Detection of IgE-specific Antibodies}

This study used D. pteronyssinus as anti-HDM allergens, allergens kit commercial from IMMULITE $® 2000$ 3 gAllergy ${ }^{\mathrm{TM}}$ specific IgE Universal kit (Siemens Healthcare GmbH, Erlangen, Germany). Levels of antiHDM IgE antibodies of L2KUN6 serum samples from 25 patients (asthma and control) were measured with the Immunochemmiluminescent method using IMMULITE 2000 xpi. $^{13}$

\section{House-dust Sampling}

House dust samples were collected from homes of patients using a vacuum cleaner. ${ }^{14}$ This study used a THV-1600 vacuum cleaner (Tori Home, Bandung, Indonesia) which was modified at the end of the hose by adding a connecting pipe so that a dust plate can be installed. The dust plate used was a special $7 \mathrm{~cm}$ diameter house-dust plate from ALK laboratory (Texas, USA) with a perforated interior covered by Whatman No. 41 filter paper (Whatman plc, Buckinghamshire, UK). House dust was obtained from bedrooms (mattresses and floors) and living rooms (carpets, sofas, mattresses and floors). After vacuuming, dust was inserted into different petri dishes for each place and preserved in zip lock plastics. If there was a house with a family room using carpets and sofas or sofas and mattresses, then dust is taken and placed into the same petri dish. 


\section{HDM Sample Processing and Identification}

The sample of house dust in this study was identified by flotation technique. Because of the limitations of tools, house dust was filtered by using a tea strainer (Fain Method: $\varnothing 240 \mathrm{~mm}$ and $0.075 \mathrm{~mm}$ ). About 0.1 gram of distillate and $3 \mathrm{ml}$ of $80 \%$ ethyl alcohol were inserted into the test tube and soaked for 24 hours. The first supernatant was removed and $3 \mathrm{~mL}$ of saturated salt was added and left for 30 minutes. The second supernatant was filtered on the buchner funnel. Filter paper was examined under a microscope. Visible mites were taken by mite needles and made preparations for identification. ${ }^{14}$

\section{Data Analysis}

Statistical analysis was performed using SPSS Version 23 (IBM Corporation, New York, USA). A test of different proportions of positive and negative IgE anti-HDM levels in the persistent asthma and normal group used Crosstabs Analysis. Results of HDM examination to show the total of mites from patients' homes and mean density of mites per gram of house dust were analyzed using the Mann Whitney test. Correlation analysis of anti-HDM IgE levels and mite density based on the persistent asthma and normal group was tested by using the Rho Spearmen test.

\section{Results}

Results of the analysis of an anti-HDM IgE profile in the persistent asthma and normal group can be seen in Table 1. IgE anti-HDM levels was measured based on a cut of point value $(\mathrm{COP}) \geq 0.35 \mathrm{kU} / \mathrm{L} .{ }^{15}$ Data showed that in the persistent asthma group 9 of 13 patients had IgE anti- HDM while in the normal group 3 out of 12 normal patients tested were positive.
Table 1 represents a test of different proportions of positive and negative IgE anti-HDM levels in the persistent asthma and normal group. In the persistent asthma group about $69 \%$ of patients were positive and $31 \%$ of patients were negative. In a group that is clinically normal it is seen that about $25 \%$ of patients were positive and $75 \%$ of patients were negative for IgE anti-HDM.

HDM were examined from samples of house dust from each patient's home. The dust collection area in each house was carried out in two main rooms, that were the bedroom (mattress and floor) and the family room (a tool for rest and floor). Species of mites obtained from total dust collected from each location was weighed, calculated and identified. In this study, a total of 143 mites were discovered (Table 2). D. pteronyssinus is the predominant species with a total of 120 mites (83.9\%), mostly on the mattress of the bedroom. Other species obtained were Cheyletus eruditus as many as 13 mites (9.1\%), Glychipagus destructoras many as 8 mites (5.6\%), Tarsonemus and Haematogama only 1 mite $(0,7 \%)$. The HDM images are shown in Figure 1.

HDM examination results showed that the total of mites in the homes of persistent asthma patients were up to 81 mites (med: 4; min: 1; max: 30), and had a tendency to be higher than the number of mites from normal patients that were found as many as 62 mites (med: 1; min: 1; max: 40), with Mann Whitney Test, $p=0.06$ (Figure 2). The dust-mite density per house dust in the homes of persistent asthma patients (med: 5.13; min: 1.96; max: 22.39) were inclined to be higher than the density of mites per gram of house dust from normal patients' homes (med: 2.35; min: 1.49, max: 24.39), with Mann Whitney Test, $p=0.07$ (Figure 3).

To determine whether or not the anti-HDM IgE levels in patients were influenced by the distribution of the number and density of mites received from the patient's homes, a

Table 1. Different proportions of positive and negative anti-HDM IgE levels in the asthma persistent and normal group.

\begin{tabular}{lccc}
\hline \multirow{2}{*}{ Subjects } & \multicolumn{2}{c}{ IgE Anti-HDM Status } & \multirow{2}{*}{ Total } \\
\cline { 2 - 3 } & $\begin{array}{c}\text { Negative IgE } \\
\text { Anti-HDM }\end{array}$ & $\begin{array}{c}\text { Positive IgE } \\
\text { Anti-HDM }\end{array}$ & \\
\hline Persistent Asthma & $4(30.8 \%)$ & $9(69.2 \%)$ & $13(100.0 \%)$ \\
Normal & $9(75.0 \%)$ & $3(25.0 \%)$ & $12(100.0 \%)$ \\
Total & $13(52.0 \%)$ & $12(48.0 \%)$ & $25(100.0 \%)$ \\
\hline
\end{tabular}


Table 2. The identification of HDM.

\begin{tabular}{lcccccc}
\hline \multirow{2}{*}{ Subjects } & \multicolumn{5}{c}{ House Dust Mite Species } & Total \\
\cline { 2 - 6 } & $\begin{array}{c}\text { Dermatophagoides } \\
\text { pteronyssinus }\end{array}$ & $\begin{array}{c}\text { Cheyletus } \\
\text { eruditus }\end{array}$ & $\begin{array}{c}\text { Glychipagus } \\
\text { destructor }\end{array}$ & Tarsonemus & Haematogama & \\
\hline Persistent Asthma & 74 & 3 & 3 & 0 & 1 & 81 \\
Normal & 46 & 10 & 5 & 1 & 0 & 62 \\
Total & 120 & 13 & 8 & 1 & 1 & 143 \\
\hline
\end{tabular}

correlation analysis was performed between anti-HDM $\operatorname{IgE}$ levels in the serum of patients with the number or density of the mites at the sampling sites within the patient's home. The result of correlation analysis showed that there was a positive correlation between IgE anti-HDM levels in the patient serum with the dust density of bedroom spaces (Rho Spearmen, $\mathrm{R}=0.35, p=0.04$ ) in Figure 4. These results suggest that the higher the density of house-dust mites, the higher anti-HDM IgE levels in the patients' serum.

\section{Discussion}

House-dust mites are the main source of allergens, and more than $50 \%$ of allergic diseases are caused by HDM. ${ }^{16} \mathrm{HDM}$ species that have been widely studied and play an important role in the development of asthma are D. pteronyssinus and $D$. farinae that can be obtained at home. Allergy testing, allergen avoidance, and allergen identification can contribute in improving asthma symptoms. Many studies have shown that some asthma patients are sensitized by
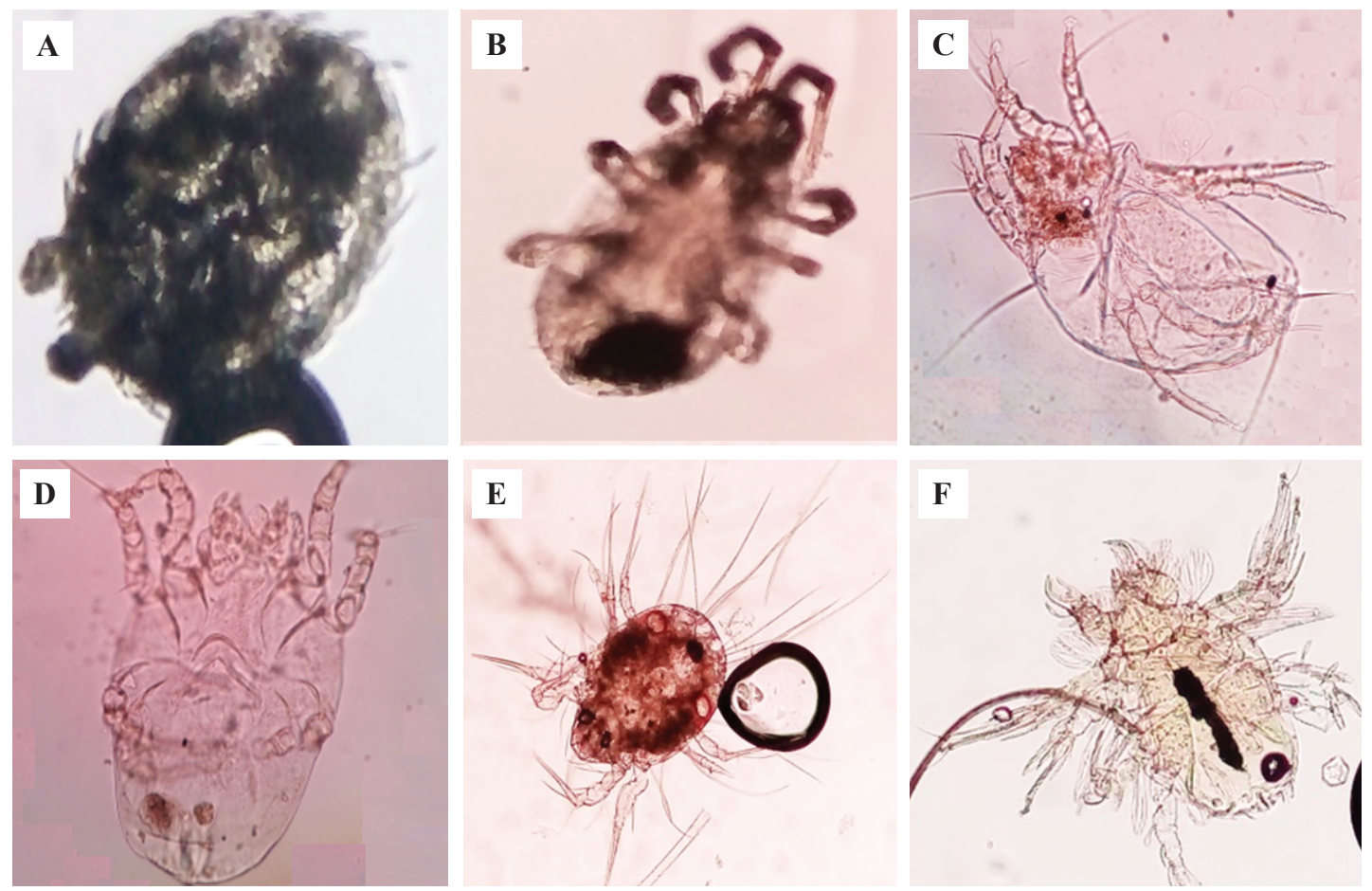

Figure 1. The images of HDM types. A: Tarsonemus; B: Haematogama; C \& D: Dermatophagoides pteronyssinus; E: Glychypagus destructor; F: Cheyletus eruditus. 


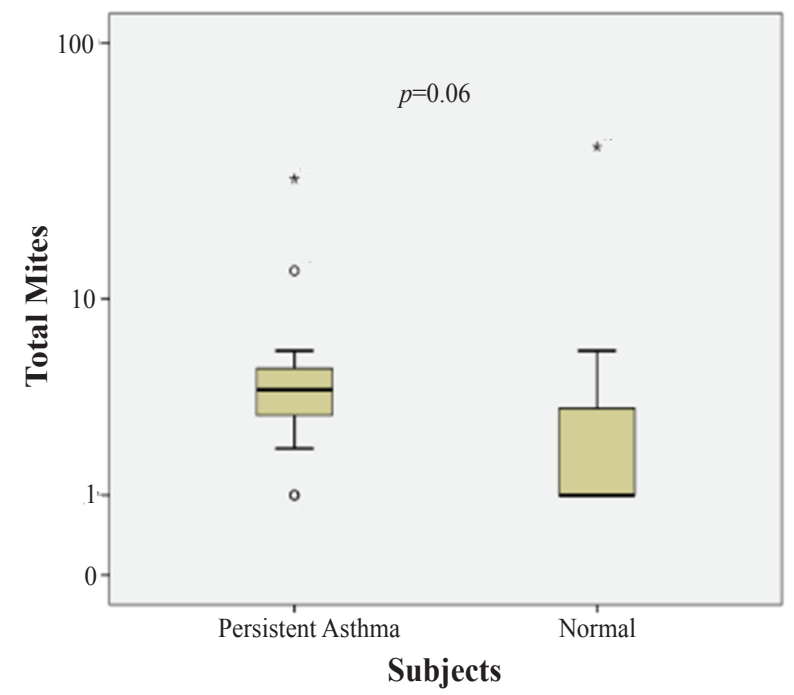

Figure 2. Total of mites from patient's home.

Dermatophagoides spp. HDM exposure as a cause of allergic asthma should be controlled as an important step to reduce clinical symptoms and prevent the development of asthma. ${ }^{2,11,12}$

In some previous HDM studies, allergens that were frequently studied were $D$. pteronyssinus, $D$. farinae, and Blomia tropicalis. ${ }^{17,18}$ This study only used one type of HDM allergen, that is D. pteronyssinus. This is one of the limitations of the study, but at the same time becomes the basis of consideration because $D$. pteronyssinus is generally the main HDM.

In this study, a test of different proportions of positive and negative IgE anti-HDM levels was carried out to determine the profile of serum IgE anti-HDM levels. The results showed that $69 \%$ of the persistent asthma group had anti-HDM IgE. This shows that about $69 \%$ of asthma patients are caused by HDM allergens while $31 \%$ of other asthma patients can be caused by other allergens. In a group that is clinically normal it is seen that about $25 \%$ of patients were positive for IgE anti-HDM and $75 \%$ of patients were negative. This is in line with research conducted in Turkey which showed that $76 \%$ of asthma patients and $38.7 \%$ of control patients had positive IgE anti-D. pteronyssinus. ${ }^{18}$ Other studies also showed that $51.7 \%$ of asthma patients had positive IgE anti-D. pteronyssinus. ${ }^{15}$ Based on these results it can be concluded that more than a half of asthma is caused by HDM allergens.

The most predominant species of mites were from Jakarta and Depok, with 54 D. pteronyssinus mites found in Jakarta and 66 mites in Depok. The total number of $D$. pteronyssinus is 120 mites. This study is in line with studies in Taiwan and Hong Kong showing that the most widely obtained mites are D. pteronyssinus. According to previous report, the dominant HDM in most areas of central Jakarta is Dermatophagoides spp. ${ }^{15}$ In contrast, studies in China show that $D$. farinae is the most widely discovered mite. ${ }^{16}$ The differences of findings on the distribution and abundance of mite species may be influenced by geographical factors such as latitude, season, climate, rainfall, altitude, and distance from the coast, as well as household factors such as an environmental location, age of buildings and materials, ventilation and thermal systems, economic conditions, foliage around the house, type of furniture, and the number of occupants. ${ }^{16}$

An international conference of HDM states that there is a correlation between the concentration of HDM/ gram of dust with the level of HDM allergens. Indonesia's environmental conditions have temperatures and humidity that support HDM to live. However, complete data on the concentration of HDM/gram in various parts of Indonesia are still limited. According to prior study, Central Jakarta has low concentration of HDM/gram dust allergens (0.29 $\mu \mathrm{g} / \mathrm{g}$ dust) compared to Australia $(6.50 \mu \mathrm{g} / \mathrm{g}$ dust $)$ and New Zealand ( $>10 \mu \mathrm{g} / \mathrm{g}$ dust). ${ }^{19}$ Differences in allergen levels or HDM levels are thought to be related to lifestyle, in addition to being related to the environment. In the developed countries that have four seasons, during the winter season, people use carpets on the floor, and the room is always closed. This situation caused HDM to develop well. ${ }^{19}$

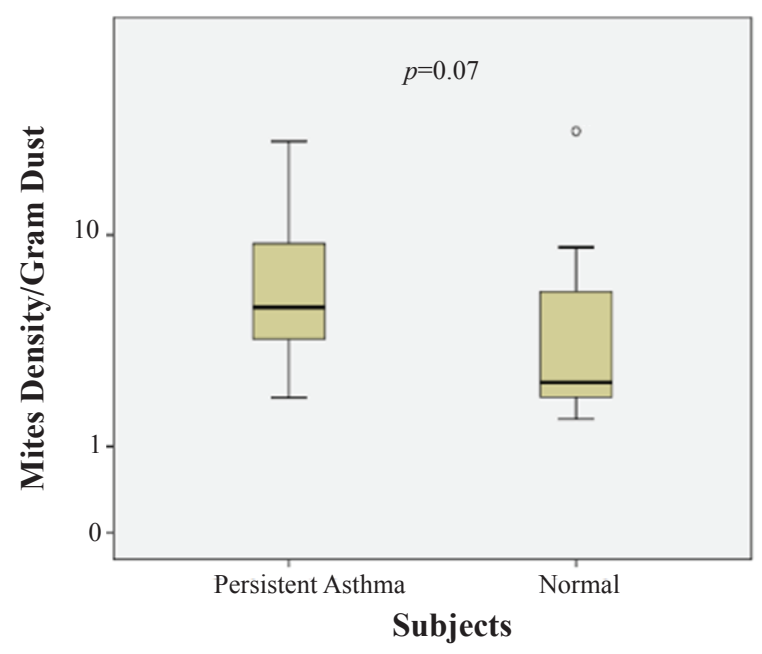

Figure 3. Average of mites density per gram of house dust. 


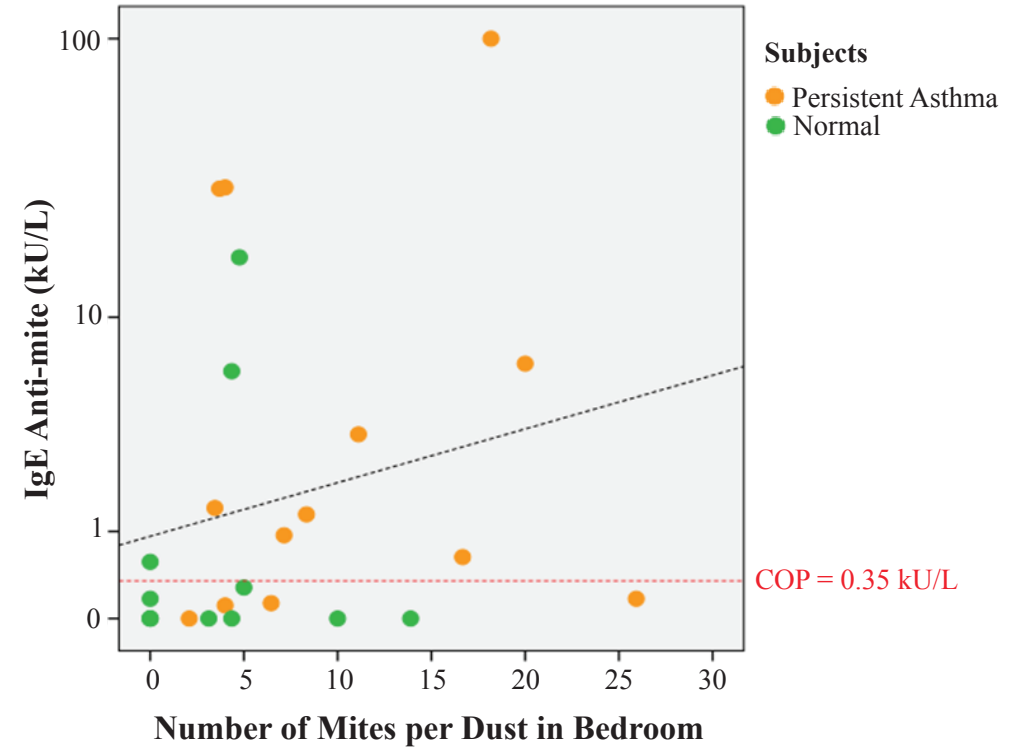

Figure 4. Correlation of IgE levels of antimite and density of mites by persistent asthma and normal group.

Meanwhile, the high level of HDM in developing countries is more related to environmental conditions which are relatively more dusty and inadequate levels of individual or family hygiene, especially in terms of cleanliness of the house.

Correlation analysis of IgE anti-HDM levels in the patient's serum with the number or density of mites at the sampling location in the patient's house was conducted to see whether the IgE anti-HDM levels were influenced by distributions of the number and the density of mites. The results of the analysis in Figure 4 show a fairly significant positive correlation between IgE anti-HDM levels in the serum of patients with the mite density in dust obtained from the bedroom The results showed that the higher the HDM density in the patient's mattress, the higher the level of IgE anti-HDM in the patient's serum.

\section{Conclusion}

Patients with positive IgE anti-HDM in the persistent asthma group (69\%) are higher than those in the clinically normal group (25\%). The density of mites is dominated by D. pteronyssinus. The density of mites in the bedroom dust has a positive correlation with the serum IgE anti-HDM levels in persistent asthma patients.

\section{Acknowledgements}

The author thank to the polyclinic of Pulmonary of Persahabatan Hospital, Graha Permata Ibu Hospital, and Prodia Laboratory.

\section{References}

1. Lynden-van Nes AMT van, Koren LGH, Snijders MCL, Bronswijk JEMH van. Medical impact of arthropod allergens. In: Wildey KB, editor. The 2nd International Conference on Insect Pests in the Urban Environment. Exeter: BPC Wheatons; 1996. p.17-30.

2. Baxi SN, Phipatanakul W. The role of alergen exposure and avoidance in asthma. Adolesc Med State Art Rev. 2010; 21(1): 57-71.

3. Sari CYI. Inflamasi alergi pada asma. CDK. 2013; 40(8): 585-8.

4. Faiza A. Hubungan antara lama penggunaan kasur kapuk dengan jumlah tungau debu rumah di perumahan PJKA Kelurahan Randusari Semarang. Semarang: Universitas Diponegoro; 2006.

5. Purba ISE, Pijoh VD, Runtuwene J. Survey perilaku masyarakat terhadap populasi tungau debu rumah di Kelurahan Titiwungen Selatan Kecamatan Sario Kota Manado. Jurnal e-Biomedik. 2013; 1(1): 319-24.

6. Natalia D. Peranan alergen tungau debu rumah (Der $\mathrm{p} 1$ dan Der $\mathrm{p} 2$ ) dalam reaksi alergi. CDK. 2015; 42(4): 251-5.

7. Fernández-Caldas E, Inmunotek SL, Puerta L, Caraballo L, Lockey RF. Mite allergens. In: Allergens and Allergen Immunotherapy. Florida: CRC Press; 2014. p.181-201.

8. Yu SJ, Liao EC, Tsai JJ. House dust mite allergy: environment evaluation and disease prevention. Asia Pac Allergy. 2014; 4(4): 241-52.

9. Bakolis I, Heinrich J, Zock JP, Norback D, Svanes C, Chen CM, et al. House dust-mite alergen exposure is associated with serum specific IgE but not with respiratory outcomes. Indoor Air. 2015; 25(3): 23544.

10. Arlian LG, Thomas AE. The biology of dust mites and the remediation of mite allergens in allergic disease. J Allergy Clin Immunol. 2001; 107(3): S406-13

11. Calderon MA, Linneberg A, Tebbe JK, Blay FD, Rojas DH, Virchow JC. Respiratory allergy caused by house dust mites: what do we really know?.J Allergy Clin Immunol. 2015; 136(1): 38-48.

12. Vallance G, McSharry C, Wood S, Thomson NC. House dust mite control measures in the treatment of asthma. Ther Clin Risk Manag. 2006; 2(4): 347-54. 
13. Customer Education and Communications. IMMULITE® 2000/2500 operators. Erlangen: Siemens Medical Solutions Diagnostics; 2007.

14. Aulung A, Djaja B, Widjaja M, Tjokronegoro A. Penggunaan teknik isolasi pada pemeriksaan tungau debu rumah. Medika. 1986: 2: 161-5.

15. Susanto AJ, Rengganis I, Rumende MC, Harimurti K. The differences in serum quantitative specific IgE levels induced by Dermatophagoides pteronyssinus, Dermatophagoides farinae and Blomia tropicalis sensitization intermittent and persistent allergic asthma. Acta Med Indones. 2017; 49(4): 299-306.

16. Yu JM, Luo QH, Sun JL, Shi CL, Yin J, Zhou YL, et al. Diversity of house dust mite in Xishuangbanna Dai, a tropical rainforestregion in Southwest. BioMed Research International. 2015: 2015; 421716. doi: $10.1155 / 2015 / 421716$.

17. Zhang C, Li J, Lai X, Zheng Y, Gjesing B, Spangfort MD, Zhong $\mathrm{N}$. House dust mite and tungau gudang IgE reactivity in allergic patients from Guangzhou, China. Asian Pac J Allergy Immunol. 2012; 30(4): 294-300.

18. Zeytun E, Dogan S, Ozcicek F, Unver E. Sensitivity to house dust mites alergens in patients with allergic asthma in Erzincan Province, Turkey. Turkiye Parazitol Derg. 2017; 41(1): 34-41.

19. Sundaru H. House dust mite alergen level and alergen sensitization as risk factors for asthma among student in Central Jakarta. Med J Indo. 2006; 15(1): 55-9. 